\title{
Carta e diário no século XIX: influências e confluências*
}

\author{
Letter and diary in the $19^{\text {th }}$ century: influences and confluences \\ Brigitte Diaz \\ Universidade de Caen - Baixa-Normandia - França
} $\diamond$

\begin{abstract}
Resumo: O presente artigo pretende apresentar os fenômenos de interação e de intercâmbio entre carta e diário, escritas na aparência divergentes, ao longo do século XIX na França. A autora analisa a singularidade de uma e de outro à luz de alguns dos parâmetros que os constituem, tais como a relação ao tempo, à escrita, ao outro e a si próprio. Por fim, os exemplos colhidos e a abordagem comparada dessas duas escritas de si demonstrarão que se trata de formas mais complementares do que rivais.
\end{abstract}

Palavras-chave: Carta; Diário; Literatura francesa século XIX

\begin{abstract}
This article tries to present the interaction and exchange phenomena between letter and diary, writings different in appearance, during the 19th century in France. The author analyses the singularity of both letter and diary, from some parameters that constitute them, e.g. the relation to the time, to the writing act, to the other, to the writer him or herself. Finallly, the selected examples and the comparative approach of these two writings of the self will show that they are more complementary than rival forms.
\end{abstract}

Keywords: Letter; Diary; French litterature $19^{\text {th }}$ scentury

Minhas cartas são uma história bastante fiel da vida. Executo sem perceber o que cem vezes desejei.

Diderot a Sophie Volland, 17 julho de 1762

Que a correspondência seja um diário inconsciente ou dissimulado e que o diário, ao contrário, seja naturalmente escrito como "carta a um amigo" é fato comprovado por muitos praticantes dessas duas formas de escrita privada. No entanto, Madame Roland, assídua epistológrafa num tempo - século XVIII - em que a prática da escrita diária não era uma atividade de mulheres, qualifica as cartas a seu marido de "diário da vida dele"1, enquanto que o jovem Henri Beyle, no início do século seguinte, pede a sua irmã Pauline, cartas escritas "como um diário [...] no qual se coloca um parágrafo por dia"2.

Entre a escrita epistolar e a escrita do diário os vasos claramente comunicam-se, apesar das divergências aparentes, tanto no modo de funcionamento enunciativo quanto nas implicações: se a carta é a priori dialógica, quando não altruísta, por necessitar da estaca do outro para se constituir, o diário atua decididamente no registro da monodia e do ensimesmamento. Haveria, então, um cruzamento quase antinatural entre a escrita centrífuga da carta, na qual compete ao scriptor fugir da "prisão do eu", como diz George Sand, para alcançar o mundo, e a escrita centrípeta do diário, do qual o outro não é simplesmente afastado, mas banido como um terceiro excluído de um tête-à-tête ciumento entre si e si. É o que sugere em forma de chiste a primeira página do diário de Gombrowicz: “Segunda, EU. Terça, EU. Quarta, Eu. Quinta, EU...”’3.

\footnotetext{
* Artigo traduzido por Ligia Fonseca Ferreira (Universidade Federal de São Paulo). O presente texto, em francês, foi orginalmente publicado em Epistolaire: Revue de L'A.I.R.E. Paris: Honoré Champion Editeur, 2006.

1 Lettres de Madame Roland, publicadas por Cl. Perroud, Imprimerie nationale, Paris. T. I, 1780-1787, 1900 ; t. II, 1788-1793, 1902. Nouvelle série: t. I, 1767-1777, 1913; t. II, 1777-1780, 1915; 4 de junho 1786, t. I, p. 614

220 de agosto de 1804 , Stendhal, Correspondance générale, edição de V. Del Litto, Honoré Champion, 1997, t. I, p. 311 (abreviado como CG). Outro pedido mais explícito do irmão à irmã: "Faz para mim em Claix um diário do que sentires cada dia. É o que desejo. Escrevamo-nos todos os dias, minha encantadora Pauline", 20 de agosto de 1805, CG, t. I, p. 311.

3 Witold Gombrowicz, Journal, t. 1, 1953-1956, Christian Bourgois éditeur, 1981, p. 63. Encontram-se outras menções a esta preocupação exclusiva consigo colocada no diário como uma muralha contra o mundo. Veja-se a injunção significativa do jovem Michelet a si próprio em seu Diário: "Eu já te disse, constroi em tua alma um muro de separação. Sem isso não há descanso. Já que sabes ser esse o segredo da felicidade, por que deixar tua alma abrir-se sem cessar para sofrer ainda mais?" (29 de agosto de 1820). E também esta observação: "Não vivo o suficiente em meu interior", 29 de junho de 1820. Ecrits de jeunesse, Journal (1820-1823) - Mémorial. Journal des idées, edição de Paul Viallanex, Gallimard, 1959
} 
Porém, diaristas ${ }^{4}$ e epistológrafos - em geral, quase sempre os mesmos $^{5}$ - não acreditam muito na alternativa exclusiva dessas posturas de escrita que, em graus variados, possuem uma mesma propensão à autoreflexividade. Eles têm muitas maneiras de atravessar a fronteira entre dois territórios limítrofes do íntimo: alguns inserem cartas a seus próximos no diário, como o jovem Michelet que restitui no diário as cartas ao seu amigo Poinsot ${ }^{6}$; outros escrevem o diário como uma longa carta a um ente querido - é o que faz Eugénie de Guérin com seu irmão: "Já que assim o desejas, meu querido Maurice, vou então continuar este pequeno diário que tanto aprecias e o terás na primeira oportunidade"7; outros ainda jogam nos dois campos, enviando o diário pelo correio como se fosse uma carta. Trata-se de um benefício duplo, como sugere Henri Beyle: "Tive a idéia de escrever meu diário o máximo possível e de enviar-te suas páginas aos poucos; duas vantagens: carta abreviadas e segurança. Mas não perde estas folhas"

Epistológrafos e diaristas são, em geral, bastante lúcidos quanto ao modo pelo qual enviesam estes gêneros que acomodam para seu uso: alguns epistológrafos fazem da carta uma espécie de diário, como a jovem Manon Philipon que com muita franqueza alerta sua correspondente sobre a autodestinação das missivas: "não te alegres em receber notícias minhas tão freqüentes; não é para ti que escrevo", embora seja a ti que me dirijo". Outros diaristas de consciência pesada acabam duvidando da falsa reclusão do "para si" do diário. Tal é o caso de Gombrowicz que, sem rodeios, se faz perguntas que atormentam muitos diaristas: "Redijo este diário a contragosto. Sua sinceridade insincera me cansa. Para quem escrevo? Se é para mim, por que destiná-lo à impressão? E se é para o leitor, por que finjo dialogar comigo mesmo?"10.

Entre essas duas formas de escrita de si, que consideraremos no limite cronológico do século XIX que foi, mais do que qualquer outro, o século do íntimo, existem decerto muitas passarelas, mas também alguns

\footnotetext{
4 N.T.= o termo "diarista" será aqui empregado como tradução do substantivo "diariste", que significa aquele ou aquela que pratica a escrita do diário, ou do adjetivo homônimo, ou seja, relativo ao diário.

5 Trata-se de um caso bastante comum entre homens e mulheres no século XIX, como o mostram alguns grandes personagens que praticaram ambas as escritas assiduamente: Stendhal, Delacroix, Sand, Marie d'Agoult, Barbey d'Aurevilly, Eugénie e Maurice de Guérin, Jules e Edmond de Goncourt, etc.

6 "Pensando bem, creio ter de incluir em meu Diário o que incluía nas minhas cartas a Poinsot. As respostas lhe retirariam um tempo útil", 5 de julho de 1820, Michelet, Écrits de jeunesse, Journal, op. cit., p. 94.

7 Eugénie de Guérin, Journal et Fragments, publicados por G.-S. Trébutien, Paris, Didier, $3^{\mathrm{e}}$ edição, 1879, p. 3.

816 de abril de $1809, C G$, t. I, p. 820.

919 de setembro de 1774, op. cit., t. I, NS, p. 223.

10 Witold Gombrowicz, Journal, op. cit., p. 63.

11 Maurice de Guérin, Journal, lettres et poèmes, edição estabelecida por G.-S. Trébutien, Paris, Didier, 1868.
}

impasses. A seguir, veremos algumas etapas desse percurso em ziguezague entre carta e diário, no qual se evidencia de modo diverso uma mesma "preocupação de si".

Se observarmos cartas e diários ao longo do século XIX e, primeiramente do ponto de vista da publicação e da recepção, essas duas formas de "ego document" comparecem na mesma categoria do íntimo. Prova disto é o fato de, em geral, serem publicadas juntas, como se procedessem não só da mesma pena, mas de um mesmo ímpeto e lógica introspectiva. Trébutien publica o Diário de Maurice de Guérin acompanhado de suas cartas ${ }^{11}$; Adolphe Brisson compõe o Diário de juventude de Francisque Sarcey servindo-se de cartas que não hesita em remanejar ${ }^{12}$. No século XIX, a carta, abandonando o antigo ofício de sociabilidade mundana que ocupava na "era Sévigné", alcança definitivamente o território do íntimo. Era o eco de um socioleto e a marca registrada de uma personagem social, porém não mais constituiria o idioleto quase críptico de uma pessoa. "Quem melhor do que a carta autógrafa revelará a mente e o coração do indivíduo?" exclamam, líricos, os irmãos Goncourt, que decifram "no papel manchado de tinta" da carta autógrafa "o enxerto em que se deposita a alma humana"13. Íntimo, forçosamente íntimo, foi assim que o século XIX sonhou a carta: "As cartas são o verdadeiro sumo do pensamento íntimo!", escreve Barbey d'Aurevilly a Trébutien ${ }^{14}$. A definição foi endossada no final do século por Gustave Lanson, que exclama: "O que é uma carta, senão movimentos da alma, instantes de uma vida apanhados pelo próprio sujeito e fixados no papel!" 15 Reescrevendo a célebre fórmula de Victor Hugo, poder-se-ia dizer que as cartas são, para as almas românticas, "tudo o que há de íntimo em tudo", tendo assim muito pouco a invejar do diário, concebido desde o princípio como "anais de uma alma" ${ }^{16}$ segundo a expressão do jovem Henri Beyle. Sob este aspecto é significativa a queixa da meiga Eugénie de Guérin que por vezes ousa pedir ao irmão um pouco mais da matéria-prima epistolar - a alma - e lhe declara,

12 Journal de jeunesse, 1839-1857, recolhido por Adolphe Brisson, Bibliothèque des annales politiques et littéraires, s. d.

${ }^{13}$ Portraits intimes du XVIII siècle, prefácio da 1a. edição, E. Dentu (18571858).

14 J. Barbey d'Aurevilly, Correspondance générale, t. IV [1854-1855], edição estabelecida por Philippe Berthier e Andrée Hirschi, Paris, Les Belles Lettres, Centre de recherches Jacques Petit, Annales de l'Université de Besançon, v. 40, p. 137.

15 Gustave Lanson, Introduction au Choix de Lettres $d u$ XVII e siècle, Hachette, 1895, reproduzida numa coletânea de artigos de G. Lanson reunida por Henri Peyre, Essais de méthode, de critique et d'histoire littéraire, Paris, Hachette, 1965, p. 279.

16 "São necessárias muitas palavras para descrever bem. Foi o que me levou a interromper este diário desde o início de julho. Seria útil escrever os anais dos nossos desejos, da nossa alma", Journal, 9 de novembro de 1807, Euvres autobiographiques, edição de V. Del Litto, Gallimard, "Bibliothèque de la Pléiade", 1981, t. I, p. 485 (grifo no texto; doravante abreviado como $O I$ ). 
em seu diário que, por sua vez, daquela matéria-prima transborda: "É de coisas íntimas que necessito"17.

Poderíamos evocar longamente os jogos de interação e de intercâmbio entre carta e diário, mas tentaremos antes avaliar a singularidade de um e outro à luz de alguns parâmetros que lhes são constitutivos - a relação ao tempo, à escrita, ao outro e a si próprio -, examinando por fim as poéticas comparadas da carta e do diário.

Carta e diário são escritas do "dia-a-dia": uma e outro datados, periódicos, marcados pela recorrência temporal. Em ambos os casos, o escrito marca uma escansão do tempo, e o inverso vale também: é o tempo que estrutura tanto a carta quanto o diário. Assim, o tempo aparece como um parâmetro essencial, ingrediente indispensável para que essas duas formas de escrita "vinguem". Para o scriptor de diários e, em menor grau para o de cartas, trata-se, inicialmente, de bem "marcar data", ou seja de datar um momento biográfico para guardá-lo na memória: "Dia 3 - hoje, nada mais do que a data"18, escreve Eugénie de Guérin, numa entrada lacônica, porém significativa de seu diário. Se a datação tem tanta importância é porque isola e faz com que exista uma fatia da vida, por mínima que seja, como sugere outra entrada no mesmo diário: "Começo colocando a data e depois veremos o que advirá na minha história de um dia"19. Segundo Georges Gusdorf, a forma escritural do diário vê seu horizonte limitado ao dia do diarista: "A verdade do diário é questionada todo dia; quem escreve um diário íntimo é o pedestre de uma vida que não se tem a pretensão de dominar; o indivíduo dispõe do direito à retificação e ao desmentido, aos humores passageiros e contraditórios" ${ }^{20}$. Mas a carta também convida a essa frequentação episódica e ambulatória de si mesmo. Se o diarista não tem a intenção de fornecer uma figuração panorâmica e definitiva de seu ser, o mesmo acontece com o epistológrafo, também ele condenado à visão míope, móvel, quase caleidoscópica que suas cartas lhe devolvem à guisa de espelho: "Minhas cartas, escreve exemplarmente Manon Phlipon, são traços da pena que colorem a sensação do momento e as idéias que dela nascem"21. A carta parece acentuar ainda o efeito de fragmentação do tempo e do eu, tão sensível no diário, pois a cada carta iniciada, é um novo diário do dia que surge, como que isolado de seu episódio anterior, assinalando para o epistológrafo a variabilidade de seu ser. À constatação que Beyle faz em seu diário - "Sou muito diarista" 22 - corresponde a de Manon Phlipon, que declara em uma carta: "Minha pena é uma temperamental que só conhece a impressão do momento" ${ }^{23}$. Mas se carta e diário são escandidos por uma mesma medida existencial - o dia do eu - ambos convidam a uma relação diferente com o tempo. Deste tempo já perdido, o diário dá conta melhor do que a carta, já que esta se volta mais para a vida sonhada e para a vida vindoura do que para a vida passada.
No diário, isso vai da simples efeméride - "Sempre de pé na mesma hora; - vestido e tendo trabalhado até as duas horas, conforme a economia de meus dias; - interrompido somente pelo almoço, ingerido rapidamente na própria mesa onde escrevo" 24 - ao cálculo obsessivo do ritmo e da duração da existência, como aquele a que se entrega Eugénie de Guérin:

Ocupando-me de cálculo há pouco, queria saber o número de meus minutos. É assustador 168 milhões e alguns milhares. Já tanto tempo de minha vida! Compreendo melhor toda a rapidez, agora que a meço em parcelas. $\mathrm{O}$ [rio] Tarn não acumula mais rápido do que isso os grãos de areia em suas margens. Meu Deus, que fizemos desses instantes que o Senhor também um dia contará? 25

É sem dúvida com a finalidade de exorcizar essa inquietante fluidez do tempo que o diarista conta escrupulosamente os dias, como sugerem estas metáforas melancólicas de Barbey d'Aurevilly ao evocar como retoma seu Memorandum após uma interrupção acidental: "Desde aquele dia, a vida correu igual em sua bacia de mármore frio. Hoje, volto para jogar novamente minha folha de salgueiro sobre as ondas que tão rapidamente se vão". ${ }^{26}$ Contra o tempo, seus avanços e desgaste, o diarista registra, arquiva, compila os minutos de sua vida, "enterra-se nos detalhes", ${ }^{27}$ como diz Barbey. [George] Sand, mais epistológrafa do que diarista, percebe-o assim: "escrever um diário é renunciar ao futuro", 28 enquanto que para Amiel, escrever um diário é "existir fora do tempo". ${ }^{29}$ Um século mais tarde, encontramos o

\footnotetext{
${ }^{17}$ Eugénie de Guérin, Journal et Fragments, publicados par G.-S. Trébutien, Paris, Didier, $3^{\mathrm{e}}$ edição, 1879 , p. 204. Ver também esta entrada de $1^{\circ}$ de maio de 1837: "É aqui, meu amigo, que quero retomar essa correpondência íntima que nos agrada e nos é necessária, a ti no mundo, a mim em minha solidão. Lamento não tê-la continuado, agora depois de ler tua carta em que me dizes porque não me havias respondido. Eu temia aborrecer-te com os detalhes de minha vida, vejo que é o contrário", p. 119.

18 Ibid., p. 20.

19 Ibid., p. 27

${ }^{20}$ Georges Gusdorf, Lignes de vie 2, Auto-bio-graphie, Éditions Odile Jacob, 1991, p. 264.

${ }^{21}$ Carta a Sophie, 7 de fevereiro de 1777, op. cit., t. II, N.S., p. 31

22 Journal, 10 de junho de 1803, OI, t. I, p. 44.

${ }^{23}$ Carta a Sophie, 22 de janeiro de 1775 , op. cit., t. I, N.S., p. 259

24 Barbey d'Aurevilly, Memoranda, in Euvres romanesques complètes, edição de Jacques Petit, Gallimard, "Bibliothèque de la Pléiade", 1966, t. II, p. 1049

${ }^{25}$ Eugénie de Guérin, Journal, op. cit., p. 118.

${ }^{26}$ Barbey d'Aurevilly, Deuxième Memorandum, op. cit., p. 974.

27 Barbey d'Aurevilly, Troisième Memorandum, op. cit., p. 1027

${ }^{28}$ George Sand, Entretiens Journaliers avec le très docte et très habile professeur Piffoël (1837-1841), Euvres autobiographiques, edição de Georges Lubin, Gallimard, "Bibliothèque de la Pléiade", t. II, 1971, p. 977.

29 "Não vivo no futuro, vivo bem pouco no presente, ainda menos no passado. Existo mais fora do tempo", Henri-Frédéric Amiel, Journal intime, [1879-1881], edição publicada sob a direção de Benard Gagnebin e Philippe M. Monnier, texto estabelecido par Philippe M. Monnier e Anne Cottier-Duperrex, Lausanne, L'Âge d'homme, 1994, t. XII, 10 de janeiro de 1881.
} 
mesmo eco em [Michel] Leiris, cuja motivação profunda e oculta à escrita de si mesmo é a luta com o passar do tempo: "Pesando tudo, parece que, quando escrevo, é sobretudo contra o próprio tempo que me exaspero" 30 . Porém, lendo as queixas insistentes dos diaristas, trata-se de um combate vão: "Valeria a pena marcar o tempo ? É escrever no pó"31, desola-se Eugénie que não descarta sua marcação temporal. Assim acontece com Barbey d'Aurevilly, que abre seu primeiro Memorandum com uma alternativa desesperadora: não manter um diário e deixar a vida perder-se no "abismo das coisas"; manter um diário e condenar-se a encarar a ruína que toda existência significa:

Desde o último Diário que escrevi durante uma viagem, há um ano numa hora similar, o que fiz e o que me tornei? Se tivesse escrito a rotina de meus dias e os dois ou três acontecimentos que já são um passado furiosamente afundado no abismo das coisas, e o que estes acontecimentos produziram em mim ou arrancaram de mim, seria uma longa e triste história cuja leitura eu não aconselharia a ninguém, nem a mim mesmo neste momento. Existem ruínas que ninguém vê acabando de desabar, quedas silenciosas. Só muito mais tarde notamos que não há mais nada onde havia uma existência e que o vazio engoliu átomos do último $\operatorname{caco}^{32}$.

O diarista persegue, então, uma tentativa aleatória de resgate e capitalização do tempo ${ }^{33}$, e é igualmente

\footnotetext{
30 Michel Leiris, La Règle du jeu, NRF, 1948, p. 242.

${ }^{31}$ Eugénie de Guérin, Journal, op. cit., p. 82.

32 Barbey d'Aurevilly, Premier Memorandum, op. cit., p. 737.

33 Béatrice Didier insiste nesse protocolo de capitalização operado pelo registro diarista: "O diário não é só um meio de capitalizar as lembranças, os dias e o eu ; é em si mesmo um capital ; e um capital que cresce num ritmo bastante satisfatório desde que o diarista seja minimamente regular: para tantos dias perdidos, tantas páginas ganhas", Le Journal intime, PUF, 1991, p. 55.

34 "O diário não é essencialmente confissão, relato de si mesmo. É um Memorial. Do que o escritor deve se lembrar ? De si mesmo ? Do que ele é, quando não escreve, quando vive a vida cotidiana, quando está vivo e verdadeiro, e não moribundo e sem verdade", Maurice Blanchot, L'Espace littéraire, Gallimard, col. "Idées", 1955, p. 20.

${ }^{35}$ Ver as reflexões de Amiel a respeito de seu diário: "Para mim é o único meio de encontrar qualquer coisa de meu passado, pois nem as semanas, nem os meses, nem os anos me servem para recortar a existência e classificar minhas lembranças", Journal intime, op. cit., t. III, 13 de dezembro de 1859.

36 Journal 18 de janeiro de 1805, OI, t. I, p. 191.

37 Carta a Sophie, 7 de fevereiro de 1777, op. cit., t. II, n.s., p. 31.

${ }^{38}$ Alguns pedem para suas cartas serem devolvidas depois de lidas por seus destinatários. É o procedimento adotado sem cerimônia por Proust; mas na verdade para ele se trata em geral de se certificar que suas mensagens serão destruídas. Vejam-se igualmente as observações de Manon Phlipon: "Encontrei nos meus alfarrábios algo que te envio, é ainda o que chamo de resultados, a digestão das minhas leituras, as loucuras de minha imaginação, peço-te apenas para conservá-lo bem como as cartas em que te mando citações ou notas, pois nem sempre conservo cópias e talvez um dia terei vontade de saber quais eram minhas jovens idéias", 2 de outubro de 1776, op. cit., t. I, n.s., p. 496.

3911 de maio de $1804, C G$, t. I, p. 134.

${ }^{40}$ Paul Valéry, Cahiers, edição estabelecida por Judith Robinson, Gallimard, "Bibliothèque de la Pléiade", 1973, t. I, p. 184.
}

neste sentido que ele "marca data", porém desta vez consigo mesmo: com quem ele fora, pois o diário é um "Memorial" 34 , um relicário de si a ser conservado para ser exumado posteriormente ${ }^{35}$; com quem ele será, figura que já se delineia no horizonte temporal do diário. Assim, Henri Beyle interpela em seu diário o leitor futuro que ele próprio se tornará, esse alter ego vindouro que saberá discernir sem complacência os artifícios de sua sinceridade: "Escrevo unicamente para a felicidade de meus filhos e para me garantir da avareza daqui a trinta anos. Diga, no fundo do coração, se não enrubesces lendo isso em 1835?"36 Assim, o diário não é um "rascunho de si”, para retomar a metáfora de Philippe Lejeune, mas a existência é que seria um rascunho do diário, convocado para arrumá-la um pouco.

Quanto à carta, a preocupação de memorizar e capitalizar o tempo é menos predominante ou, em todo o caso, não se dá como motivação primeira, pois as cartas, segundo a bela expressão de Madame de Sévigné, se escrevem na "pena dos ventos". Compreenda-se que o vento da disseminação sopra sobre essas escritas de si. Desprovidas de qualquer capitalização, as cartas são escritas da perda, de uma perda aparentemente aceita pelo epistológrafo que pratica, através dos traços efêmeros de si mesmo, uma exploração aleatória de seu ser em transformação. A escrita da carta, que se dá facilmente como um gesto maquinal, abre uma página de liberdade na qual se registram as ranhuras inconstantes das impressões do momento: "Tão logo se vão, escreve Manon Philipon sobre suas missivas, mal recordo o que continham" ${ }^{37}$. Mas devemos confiar nesta bela prodigalidade? Sabemos perfeitamente que os epistológrafos manifestam-se exaustivamente contra o desaparecimento programado de seus escritos: desde os rascunhos, os minutos, até a conservação das $\operatorname{cartas}^{38}$, às vezes exigida como cláusula da correspondência: "Não perde minhas cartas, escreve Henri Beyle a sua irmã, elas nos serão úteis a ambos: a ti, que poderás compreender na sequência o que de início não percebeste, e a mim, contarão a história de meu pensamento" 39 . Portanto, a carta pode identificar-se com o diário nesta função memorial que ela sempre mantém de reserva e, ao inverso, existem diários que praticam a virtude do esquecimento e diaristas avessos a essa contabilidade existencial, sintoma de um mal disfarçado egotismo. É o caso de [Paul] Valéry que se recusa a anotar em seu diário o anedótico, o biográfico, o pessoal e se reivindica, ao contrário, como "um homem sem data" 40.

Se as oposições entre carta e diário são flutuantes e pouco pertinentes em relação à gestão do tempo, elas também o são no que diz respeito aos protocolos da escrita que as definem. À preocupação da memorização e da capitalização de si corresponde no diarista a escolha do caderno ou da caderneta portátil que é conservada 
preciosamente como o guardião dos minutos de sua existência: "Mudo o formato de meu Diário, esclarece Eugénie de Guérin, para deixá-lo mais cômodo no bolso onde o colocarei durante minhas compras" ${ }^{41}$. Nada disso acontece na carta que é, como escreve Proust, "o companheiro de um dia que nunca mais vamos rever" 42 .A folha solta da carta desaparece, o jornal permanece: uma é feita para se desprender de si, outra para ficar colada a si. Conservado, arquivado, o diário se oferece, assim, a possíveis releituras: é a prática de Henri Beyle que relê, anota e comenta as páginas antigas, compondo assim um amontoado de escritos que revelam as camadas sucessivas de uma personalidade em transformação, propícias a algumas escavações arqueológicas. Porém, ainda neste caso, as diferenças não são tão nítidas; e pode acontecer da carta - mais do que o inverso - tomar a forma material do diário para assumir algumas das funções deste. É por isso que Beyle convida sua irmã Pauline a reunir suas cartas e colocá-las em cadernetas nas quais ela possa anotar reflexões na margem, a exemplo do que ele mesmo pratica: "Talvez seria bom teres um caderno e nele copiares as cartas, deixando espaço para anotações"43.

Se o suporte da carta e do diário obviamente não é o mesmo, a cerimônia de escrita que acionam também difere. Trancado em sua fortaleza interior, "escondido atrás de uma barricada" dentro de si, como escreve Maurice de Guérin ${ }^{44}$, o diarista pratica voluntariamente a religião do segredo. É o caso de Stendhal, este "insular do Eu" como dizia Valéry ${ }^{45}$, que se forja todo um arsenal de códigos, linguagens cifradas e outras barreiras para inibir ou impedir qualquer intrusão em seu diário que ele define como sendo sua "consciência íntima" 46 . Neste aspecto, dada a própria fragilidade que a viagem lhe confere, a carta despreza constantemente a cláusula do segredo que o autor de cartas infringe pelo simples gesto de se abrir ao outro. Mas, naturalmente, existem segredos que se dão melhor no dueto epistolar do que no isolamento do diário. Assim, para o jovem Henri Beyle, em seus anos de rebelião familiar, o segredo é a condição sine qua non da correspondência, bem como seu estímulo. A exemplo do diário, a correspondência edifica-se sobre um segredo, porém um segredo mais dramaticamente encenado, pois são dois a guardá-lo: "A certeza que me dás de que minhas cartas jamais serão vistas faz com que eu te diga tudo" ${ }^{\prime 7}$. A estas cartas secretas opõem-se simetricamente os diários dirigidos; alguns são escritos expressamente para serem lidos por outros. É na forma de carta que Barbey d'Aurevilly redige o diário destinado a seu amigo Trébutien:

Caen, Hotel Lagouelle, 28 de setembro de 1856.

Trébutien quer que eu the faça um Memorandum de todos os dias que passarei em Caen e, para mim, o que
Trébutien quer, Deus quer ! Recomeço então para ele, o que havia feito para Guérin em outra época ${ }^{48}$.

O que Trébutien quer: este início do terceiro Memorandum desestabiliza o protocolo solipsista e um tanto astênico do diário na dinâmica do desejo que reage a troca epistolar ${ }^{49}$, como se Barbey tentasse reanimar a escrita mórbida do diário, "esta sepultura de cada parcela de vida". ${ }^{50}$ Escrever o diário em forma de carta é instaurar a lei do desejo onde só reinavam - ao menos para Barbey a exigência de um dever a cumprir e o tédio profundo "de se curvar sobre todos os nadas que compuseram um dia" 51 , atravessado somente pela obsessão de continuar mesmo assim o labor de escrivão: "é uma febre intermitente minhas anotações neste Diário" 52 . No entanto, e Barbey não o ignora, ainda que "encomendado" pelo outro, o diário não se confundiria com a carta, escrita, por sua vez, no calor e na urgência do desejo pelo outro. Ele explicita claramente a diferença de regime entre essas duas escritas, explicando que renunciou dirigir seu Memorandum ao "Anjo Branco", a mulher amada, pois com ela "tudo vira carta”, e então é uma outra história que se escreve:

Um Memorandum das coisas passadas, - esta sepultura de cada parcela de vida, pois aqui, nós nos enterramos em detalhes, - apaga-se na onipresença dos sentimentos. Em vez de pensar, à noite, sobre a recapitulação dos minutos do dia e de seu emprego, pensamos naquela para quem escrevemos e é dela que vamos falar, ao invés de falar de outra coisa. - $\mathrm{O}$ amor é exclusivo demais, imperioso demais, jaculatório demais; expressa-se demais na segunda pessoa, para que com ele o Memorandum seja possível. Não existe

41 Eugénie de Guérin, Journal, op. cit., p. 106.

42 Correspondance de Marcel Proust, edição apresentada, estabelecida e anotada por Philip Kolb, Plon, 1970-1993, t. II, p. 299.

43 Julho de $1804, C G$, t. I, p. 182. Encontra-se igualmente este tipo de conselho por parte de Goethe a sua irmã Cornélia: ele lhe pede para escrever apenas em metade da página a fim de que ele possa anotar e comentar a mensagem para em seguida reenviá-las.

44 "Quero me entrincheirar em mim, me emparedar para me livrar de toda tentação, não mexendo em mais do que um termo, mesmo que eu seque de pé“, 4 de julho de 1833, Journal, op. cit., p. 43

45 Paul Valéry, "Stendhal ", artigo reproduzido em Variétés, Euvres, Paris, Gallimard, "Bibliothèque de la Pléiade", 1957, t. I, p. 566.

46 "Se algum indiscreto ler esse jornal, eu lhe retirarei o prazer de se mofar de mim fazendo-o notar que o que deve ser o registro matemático e inflexível de minha maneira de ser, não adulando nem maldizendo, mas enunciando pura e severamente o que acredito que foi. Está destinado a me curar de meus ridículos quando eu o reler em 1820”, junho de 1810 $O I$, t. I, p. 579

4714 de julho de $1809, C G$, t. I, p. 835

48 Barbey d'Aurevilly, Troisième Memorandum, op. cit., p. 1027.

49 Mesmo a tímida Eugénie sabe suspender a pena para aguçar a espera de seu irmão bem-amado: "Pensaste que eu não queria mais escrever-te, que não queria mais tua amizade. Eu aqui te escrevia todos os dias, mas queria te dar tempo para desejar receber uma carta", Eugénie de Guérin, Journal, op. cit., p. 136.

50 Barbey d'Aurevilly, Troisième Memorandum, op. cit., p. 1027

51 Barbey d'Aurevilly, Premier Memorandum, op. cit., p. 740

52 Ibid., p. 860. 
história fora da mulher amada, e o Memorandum é uma história... ${ }^{53}$.

Entretanto, para ele, o Memorandum permanecerá sempre ativado pelo destinatário:

Recomeçarei um diário ? - Por que não, já que G[uérin] o deseja ? Deus sabe que ele é o único homem a quem os fragmentos de minha vida interessam e fazem pensar. Precisei lembrar-me disso para retomar meus dias um a um ${ }^{54}$.

Tais hesitações sobre o destino - escrever para si ou para o outro? - são os sintomas mais patentes do parentesco entre carta e diário. Aí se cruzam expectativas confusas, difíceis de serem destrinçadas pelo próprio escritor. Se o diarista naturalmente inventa destinatários - ou, como Barbey d'Aurevilly, se reconhece-lhes a existência dentro de si próprio (Maurice de Guérin escreve: "este homem penetra dentro de mim cada vez mais e se incrusta até o coração. Destino-lhe um diário de minha errância") ${ }^{55}$ - o epistológrafo, simetricamente, às vezes desvia, passando pelo outro para chegar a si mesmo, i.e. o único destinatário verdadeiro de suas confidências. As cartas de Beyle a Pauline constituem um exemplo interessante do que parece ser um desvio da carta em diário. A correspondência oferece-se, da mesma forma que o diário por ele mantido em estereofonia, como um formidável terreno de experiências onde se pode testar, como protótipos diversos, os ideais efêmeros do eu. A pretexto de formar a jovem Pauline ${ }^{56}$, é a si mesmo que Beyle se dirige. Acontece então que, ao apagar a presença de sua correspondente, ele se coloca explicitamente como destinatário de seu próprio ensinamento. Ao cabo de uma meditação proposta à irmã, ele conclui: "Preciso inculcarme estas máximas, pois meu caráter apaixonado delas me afasta incessantemente" 57 . No limite, desaparecem da carta os sinais mais elementares da comunicação epistolar (endereços, interpelações, fórmulas fáticas, etc.,) para dar lugar às reflexões que Beyle poderia muito bem ter apontado em seu diário, como ele mesmo observa: "Eis, minha querida Pauline, quatro páginas de filosofia que acabo de escrever no papel de carta, em vez de colocá-las em meu caderno. Eu precisava encontrar uma verdade nova e eis o caminho para alcançá-las: muitos exemplos" 58 . Papel de carta ou caderno? Correspondência ou diário? A diferença é tênue. Se o suporte e a situação de enunciação mudam, os discursos ali produzidos são finalmente bem próximos e seus horizontes tendem a se unir.

Carta e diário têm em comum algumas funções que se dividem desigualmente. Emprestando uma reflexão de Georges Gusdorf, é lícito dizer que essas duas práticas de escrita de si têm como horizonte teleológico comum não a ontologia - "a busca do Ser sem restrição" - mas mais humildemente "a fenomenologia, ou seja a exploração das dimensões da existência pessoal revelada a si mesma na experiência vivida"59. Exploratória e experimental, a escrita epistolar e diarista faz existir o "Eu" numa infinidade de posturas de expressão que lhe permitem afastar-se dos conformismos obrigatórios da vida social. A carta, como o diário, legitimam - e nisto reside sua principal virtude - o interesse que o indivíduo manifesta por si mesmo: "Cito-me constantemente, escreve Beyle em uma carta a Pauline, pois sou o homem cujo coração mais conheço" 60 , enquanto Marie Bashkirtseff declara sem falso pudor no incipit de seu Diário:

Podeis estar certos, caridosos leitores, que nestas páginas revelo-me por inteiro. Eu, como interesse, talvez seja pouco para vós, mas não pensais que sou $e u$, pensai que é um ser humano que vos conta todas as suas impressões desde a infância ${ }^{61}$.

Esta preocupação consigo leva diaristas e epistológrafos a idêntica observação circunstanciada de si mesmos: anedotas, resumos, micronarrativas de vida abundam tanto nas páginas da carta como nas do diário. Mas se eles se restringem a essa atenção míope voltada para o despedaçamento fatual da vida cotidiana, é porque esta supostamente os conduz à revelação de sua identidade profunda. Barbey d' Aurevilly o confirma: seu Memorandum registra muito mais "a vida de [seu] pensamento do que os fatos exteriores" ${ }^{62}$. Stendhal, por sua vez, deseja reler suas cartas passadas como "história de seu espírito". Carta e diário compõem um álbum de clichês intelectuais instantâneos, feitos para guardar a impressão de uma fagulha de vida, um fragmento de emoção, um esboço de ideia, para um dia permitir ao indivíduo reencontrar-se consigo mesmo através desses

\footnotetext{
$\overline{53}$ Barbey d'Aurevilly, Troisième Memorandum, op. cit., p. 1027. Barbey d'Aurevilly, no entanto, escreverá seu quinto Memorandum para uma mulher, , Mme de Bouglon.

${ }^{54}$ Barbey d'Aurevilly, Deuxième Memorandum, op. cit., p. 901.

55 É o que escreve em carta a Trébutien em 2 de setembro de 1835 , Correspondance générale, op. cit., t. I, p. 1467.

${ }^{56}$ Projeto que Beyle reivindica assim sem modéstia: "Eu te formo, és a filha amada de meu coração, para falar como Ossian a quem amas. Será que meditas o bastante sobre minhas cartas para delas tirar proveito?", 5 de março de $1806, C G$, t. I, p. 500.

57 Julho de 1804, $C G$, t. I, p. 181.

58 Carta a Pauline, agosto de 1804, CG, t. I, p. 196. Por sua vez, o diário é um diálogo consigo mesmo, como sugere esta reflexão intrusiva numa carta a Pauline: "Recebi a grande encomenda que me enviaste; estava numa discussão comigo mesmo provocada pela leitura da segunda edição do Traité de la manie do excelente doutor Pinel”, 29 de junho de 1810, CG, t. II, p. 44.

59 Georges Gusdorf, Lignes de vie 2, Auto-bio-graphie, Editions Odile Jacob, 1991, p. 225.

6010 de junho de $1804, C G$, t. I, p. 144.

61 Journal de Marie Bashkirtseff, edição estabelecida por André Theuriet, Paris, Charpentier, 1887, t. I. Prefácio de 1884.

62 Barbey d'Aurevilly, Deuxième Memorandum, op. cit., p. 913.
} 
ecos distantes. A função memorial é a mais comum para os diaristas e epistológrafos ${ }^{63}$, no entanto a função especular é outra: o diário também é um "espelho da alma", segundo a metáfora da carta tão emblemática quanto convencional desde Demétrio. Maurice de Guérin a retoma por sua conta, espreitando no espelho de suas páginas as metamorfoses de sua alma:

Minha alma foi meu primeiro horizonte. Há tempos o contemplo. Vejo emergir do fundo de meu ser vapores que se elevam como se proviessem de um vale profundo e que só tomam forma ao sopro do acaso ; fantasmas imperceptíveis ascendendo lentamente e sem interrupção ${ }^{64}$.

Quanto ao epistológrafo, o reflexo de si próprio observado na carta complica-se com o olhar do outro: "Ninguém mais nesta Terra, além de vós, me conhece, Trébutien ! [...] Sois minha testemunha e juiz e vivo em vossa presença melhor do que na presença de outros. Vejome sendo visto" 65 . .A fórmula descreve admiravelmente a relação especular atuando nas correspondências nas quais, segundo Michel Foucault, "trata-se de fazer coincidir o olhar do outro e o olhar sobre si mesmo"66. Logo, a exploração de si que ocorre na carta não se limita somente ao deciframento de si por si mesmo, cujo destinatário seria apenas o espectador acidental - o que reproduz mais ou menos o caso do diário dirigido a alguém. A carta é uma "abertura que damos ao outro sobre nós mesmos"67. Em outras palavras, ela não é um simples reflexo de si que se oferece para captar o olhar fascinado daquele que convocamos para este fim, mas, sim, $o$ processo de escrita pelo qual o sujeito se produz, registrando a presença e o peso de outrem na constituição de sua identidade. A imagem por demais estática do espelho corre o risco, portanto, de traduzir de forma muito aproximativa a relação complexa de figuração de si que se instaura na carta e que é, antes, uma tentativa de inteligibilidade de si do que a simples captação especular. Distanciada de seu uso primeiro - a conversa com o ausente-, a carta convida a uma pedagogia de si, função mais comumente atribuída ao diário. Retomando por sua conta própria o imperativo délfico, Beyle escreve: "Nosce te ipsum. Acredito com Tracy e a Grécia que este é o caminho da felicidade. Meu meio é este diário" 68 . Esta função cognitiva se desdobra em intenção formadora, sendo o epistológrafo e o diarista "autodidatas de si": eles querem formar-se, nascer de suas obras ou melhor, de sua pena. O diário de juventude de Beyle é habitado por este "querer ser"69, dedicado à edificação, à invenção de si. É através dele que o jovem apaixonado pela glória se propõe a tornar-se um "grande homem"70. Ele tentará iniciar sua jovem irmã Pauline na escrita de cartas, louvando-lhe os méritos desta autoformação praticada dia-a-dia no diário: "No geral, trabalha-te a ti mesma"; é o trabalho, explica ele, a coisa mais útil que encontrou para si próprio ${ }^{71}$.

Restaria ver de que forma é conduzido esse trabalho - "Trabalho minha alma", escreve Barbey d'Aurevilly ${ }^{72}$ - nas duas frentes, da carta e do diário, pois se para ambos o instrumento é o mesmo - a escrita -, o imaginário e a prática do epistológrafo e do diarista diferem sensivelmente. De forma esquemática, poder-seia dizer que a naturalidade, espontaneidade, sinceridade e autenticidade são ao mesmo tempo valores éticos e estéticos por eles compartilhados. "Escrever sem se incomodar ${ }^{73}$ ", currente calamo, é a regra de ouro da escrita epistolar. Ao longo do século romântico, a carta aparece como uma escrita antimundana e antiliterária; ela goza de um bônus de verdade inversamente proporcional ao descrédito que afeta, por outro lado, quase todas as formas da fala socializada, seja ela política, mundana ou literária. Tal espontaneidade é vivida como garantia de autenticidade - "Penso alto contigo" ${ }^{74}$ escreve Beyle a Pauline. Relendo as cartas de Trébutien, Barbey anota em seu diário: "O melhor de mim está nestas cartas, onde falo minha verdadeira língua, lixando-me para todos os públicos !"75 A voz da carta é a voz verdadeira e original, pois se exprime sem entrave e sem censura, quase maquinalmente, como sugere mais uma vez Barbey a Trébutien: "Não agradeçais minhas cartas, elas jorram de minha pena como a palavra de meus lábios, e só me custam fisicamente o tempo de escrevê-las". ${ }^{76}$ E esta palavra jaculatória, que não pesa nem se impõe, convida a uma escrita do prazer. A felicidade de escrever é a experiência mais compartilhada e mais comentada

\footnotetext{
${ }^{63}$ Ver a observação de Manon Philipon: "Não penso absolutamente que devamos queimar nossas cartas ; aposto que se o fizéssemos, acabaríamos arrependidas em alguns anos. Existem mil coisas que, se conhecidas em dado momento, nos aborreceriam, porém, mais tarde, nos agradaria revê-las", 5 de dezembro de 1775, op.cit., t. I, n.s., p. 341

${ }^{64}$ Maurice de Guérin, 30 de abril de 1835, op. cit., p. 119.

${ }^{65}$ Barbey d'Aurevilly, Correspondance générale, op .cit., t. V, p. 99

66 M. Foucault, "L'écriture de soi", Corps écrit, n 5, 1983, p. 23.

67 Ibid., p. 17.

6810 de agosto de $1811, O I$, t. I, p. 710

69 "Logo, não se trata apenas do que sou, mas no total do que eu quero ser. Escrevendo sobre mim, escrevendo-me, aprovo-me ou reprovo-me nunca sou um testemunho estranho ou indiferente. O querer ronda os confins do ser e esforça-se para se alinhar no sentido da caminhada", G Gusdorf, op. cit., p. 226.

${ }^{70}$ Ele manifesta uma confiança total na concretização desse projeto: “Que só a educação faz os grandes homens; por conseguinte, que basta querêlo para tornar-se um grande gênio", a Pauline, 30 de janeiro de 1803, $C G$, t. I, p. 79

${ }^{71}$ Ver as cartas a Pauline de 4 de janeiro de 1804 e 26 de janeiro de 1806, $C G$, t. I, p. 145 et p. 453

72 Barbey d'Aurevilly, Premier Memorandum, op. cit., p. 841.

73 É a única regra que Beyle sugere a Pauline. Mesma constatação em Manon Phlipon que declara a sua amiga: "Contigo todo constragimento se esvai, eu traço sem receio o que aparece na ponta da pena", Carta a Sophie, 20 de marco de 1772 , op.cit., t. I, N.S., p. 88.

${ }^{74}$ Carta a Pauline, 26 de fevereiro de 1805, CG, t. I, p. 257.

75 Barbey d'Aurevilly, Troisième Memorandum, op. cit., p. 1048, grifo no texto.

${ }^{76}$ Barbey d'Aurevilly, Correspondance générale, t. III, op. cit., p. 208.
} 
por esses epistológrafos de si, como escreve Manon, ao iniciar uma de suas cartas assim:

Bom dia, então, minha terna amiga, eis-me aqui tranquila e solitariamente em meu quartinho, com a pena na mão, calma e ternura no coração, deliciosamente ocupada em escrever-te, pintar meus pensamentos, expressar meus sentimentos; não consigo dizer-te o quanto esta situação me encanta. Parece que não levo mais nada em conta, todo o resto não me parece mais do que uma sombra. ${ }^{77}$

Mas como se dá esse prazer efusivo e sensual no diário? Alguns afirmam que o prazer também pode ser a principal motivação do gesto diarista: "Escrevo pelo prazer de escrever, para expor minhas ideias...", escreve Amélie Weiler, uma simples jovem do século XIX que na sequência esclarece: “...como eu as exporia a uma amiga discreta e íntima", ${ }^{78}$ fazendo de seu diário o sucedâneo de uma correspondência inexistente. Para outros, a relato cotidiano de si é mais constantemente sentido como uma obrigação: é o caso de Beyle, embora seja um diarista assíduo. O incipit de seu diário é, sob esse aspecto, significativo:

Disponho-me a escrever a história da minha vida dia a dia. Não sei se terei força para completar este projeto já começado em Paris. Eis um erro de francês; haverá muitos outros, pois tenho como princípio não me incomodar e nunca apagar. Se eu tiver coragem,

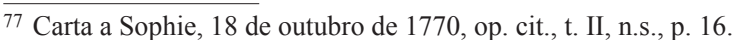

78 Amélie Weiler, Journal d'une jeune fille mal dans son siècle, texto estabelecido por Nicolas Stoskopf, Editions La Nuée bleue, 1997, p. 23.

79 Journal, 18 de abril de 1801, OI, t. I, p. 3.

${ }^{80}$ Souvenirs d'égotisme, $O I$, t. II, p. 430.

${ }^{81}$ Encontra-se esta impressão de dificuldade em manter o diário em inúmeros diaristas, e entre todos especialmente em Amiel que se queixa constantemente do tédio provocado pela fastidiosa corvéia de escrita: "No fundo, é perfeitamente entediante ocupar-se tanto de si mesmo, de se analisar, confessar, contar, como o fiz cem vezes, e aspiro ao momento em que não mais precisarei disso e poderei olhar constantemente para fora”, Henri-Frédéric Amiel, Journal, 12 de abril de 1852, Editions Complexe, 1987, p. 35.

82 Journal, 23 de setembro de 1813, OI, t. I, p. 888. Amiel também contrapõe a vida esterilizante do diário à "verdadeira vida" que ele espelha: "Esta vida virtual, ineficiente, retraída por assim dizer, me pareceu derivar da fraqueza e emprestar um travesseiro à minha preguiça de agir", HenriFrédéric Amiel, Journal, op. cit., p. 37.

83 "Eis um mal-estar completo. Não escrevo o diário quando estou feliz; esta análise atrapalha a felicidade, mas hoje nada tenho a perder", Journal, 28 de agosto de 1812, OI, t. I, p. 827.

84 "Que a felicidade não pode ser enviada numa carta ? Enviar-te-ei com prazer uma parte da minha", escreve Henri a Pauline (26 de julho de $1805, C G$, t. I, p. 300). Contrariamente ao diário, a carta é ditada pela felicidade.

${ }^{85}$ Carta a Louis Crozet, 20 de outubro de 1816, CG, t. II, p. 715. Mais um testemunho desta euforia epistolar é esta metáfora lírica, em Stendhal, da recepção da carta: "Sua adorável carta é para mim como uma jarra cheia da água mais fresca que se oferece ao viajante que atravessa penosamente as areias da África", carta a Pauline, 14 de julho de 1809, CG, t. I, p. 835.

${ }^{86}$ Barbey d'Aurevilly, Premier Memorandum, op. cit., p. 859.

87 Barbey d'Aurevilly, Troisième Memorandum, op. cit., p. 1034

${ }^{88}$ Barbey d'Aurevilly, Premier Memorandum, op. cit., p. 868.

89 Barbey d'Aurevilly, Premier Memorandum, op. cit., p. 798.
}

retomarei em 2 de Ventoso, dia em que partida de Milão ${ }^{79}$.

Longe de fluir, a prática do diário é um desafio, uma prova que exige "força" e "coragem". É necessário obrigar-se a uma assiduidade mínima; não "deflorar os momentos felizes [...] descrevendo-os, anatomizandoos" ${ }^{" 80}$ e sobretudo, não mentir sobre si. A tarefa é claramente árdua ${ }^{81}$, mesmo se a única regra retórica desses anais de si consista em "não se incomodar e nunca apagar". O tempo da escrita invade o tempo da vida e o diário se põe a devorar o que supostamente deveria elucidar: "Teu negócio é viver ou descrever tua vida? Só deves escrever um diário enquanto ele puder ajudar a viver da grande" $"$. Em contrapartida, Beyle não se faz esse tipo de pergunta em relação a sua correspondência, cuja prática nunca é estranha às alegrias da existência. Se ele "não escreve o diário quando está feliz" 83 , tal regra não vale para a carta ${ }^{84}$ que se prende, e sempre se prenderá, a certa euforia: as cartas "são uma festa", escreve ele a Crozet ${ }^{85}$. Barbey d'Aurevilly, por sua vez, nunca deixa de marcar no diário o momento de "furia" 86 da escrita da carta, e a volúpia de sua recepção. As cartas, escreve ele, são "a cordialidade de minha vida, o elixir da longevidade para meu coração"87. Longe de suscitar tais encantamentos, manter o diário o leva mais dolorosamente "ao isolamento e a uma vida fragmentada" ou, pior, à "sensação do nada" 88 , Como se o diário fosse apenas um interminável face a face com sua própria insignificância: "Deitado por volta de meia-noite, escrevo este Memorandum tão insignificante quanto o que relembra. Que tecido de banalidades é a vida!"89. Para concluir, não seria então o caso de dizer que finalmente o que distingue a carta do diário é esse estímulo do desejo desejo de se encontrar com o outro mas também consigo mesmo - nascido na troca epistolar, desejo que o diarista ignora, pelo fato de precisar entregar-se unicamente a si mesmo a fim de dar vida e sentido a um projeto cuja inutilidade quase sempre lhe pesa e se afunda, apesar das insistentes injunções superegóicas?

Talvez seja arriscado encerrar aqui a comparação entre carta e diário. Será sem dúvida necessário completar este breve apanhado das práticas que as distinguem no século XIX com um estudo mais aprofundado dos "pactos" e dos compromissos que epistológrafos e diaristas assumidos com eles mesmos e com o outro, ao registrar os anais de suas vidas. É a sequência que daremos, numa próxima série de estudos, a esta primeira etapa de uma abordagem comparada dessas duas formas de escrita de si, mais complementares do que rivais.

Recebido: 12 de março de 2014

Aprovado: 30 de março de 2014

Contato: brigitte.diaz@unicaen.fr; ligia.ff@uol.com.br 